Journal of Engineering and Applied Sciences 14 (20): 7437-7441, 2019

ISSN: 1816-949X

(C) Medwell Journals, 2019

\title{
Growth ZnO Nanorod Arrays and its Photocatalytic Activity Under Visible Light Irradiation
}

\author{
${ }^{1}$ Dinh Thi Thanh Tam, ${ }^{2}$ Tran Thi Ngoc Quyen, ${ }^{2}$ Thi Hanh Thu Vu and ${ }^{1}$ Long Giang Bach \\ ${ }^{1}$ NTT Institute of High Technology, Nguyen Tat Thanh University, \\ 298-300A Nguyen Tat Thanh, Ho Chi Minh City, Vietnam \\ ${ }^{2}$ Faculty of Physics and Engineering Physics, University of Science, VNU-HCM City, \\ 227 Nguyen Van $\mathrm{Cu}$, Ho Chi Minh City, Vietnam \\ blgiang@ntt.edu.vn
}

\begin{abstract}
In this study, visible light active Zinc Oxide Nanorod arrays ( $\mathrm{ZnO} \mathrm{NRs)} \mathrm{were} \mathrm{successfully} \mathrm{prepared}$ by an electrochemical process using $\mathrm{Al}$-doped $\mathrm{ZnO}$ film $(\mathrm{AZO})$ as an electrode, followed by annealed in ambient at difference temperature $\left(100-500^{\circ} \mathrm{C}\right)$. The as-prepared $\mathrm{ZnO}$ NRs were characterized by SEM, XRD and PL technique. From the XRD and SEM results, ZnO NRs possess hexagonal morphology with an average diameter of 50-60 nm and the average length of 1.2-1.3 $\mu \mathrm{m}$ was obtained. From PL spectrum, the annealed temperature significant effects on the surface defects in $\mathrm{ZnO}$ NRs which can be enhanced visible light absorption. Moreover, $\mathrm{ZnO}$ NRs sample annealed at $300^{\circ} \mathrm{C}$ exhibited the highest PL peak, having the highest formation rate of ${ }^{\circ} \mathrm{OH}$ radicals and the highest percentage of Methylene Blue $(\mathrm{MB})$ removal $(76.05 \%)$ under visible light irradiation. This result indicates that the formation rate of ${ }^{\circ} \mathrm{OH}$ radicals shows a good correlation with the photocatalytic activity.
\end{abstract}

Key words: $\mathrm{ZnO}$ nanorod arrays, photocatalysis, methylene blue, formation, hexagonal morphology, highest percentage

\section{INTRODUCTION}

Recently, semicondu738ctor photocatalysis techniques have been received much attention because they can completely degrade hazardous compounds in water, which can be mineralized to $\mathrm{CO}_{2}, \mathrm{H}_{2} \mathrm{O}$ and harmless inorganic anions (Alinsafi et al., 2007). Among many semiconductor nanomaterials, $\mathrm{ZnO}$ Nanorod arrays $\mathrm{ZnO}$ NRs) with hexagonal wurtzite crystal has been a potential photocatalyst for photodegradation of organic pollutants due to its high electron mobility, chemical stability and large surface (Look, 2001). However, this material only shows photo response to UV irradiation due to its large band gap $\left(E_{\mathrm{g}}=3.3 \mathrm{eV}\right)$. UV irradiation is only $3-5 \%$ of solar light and thus, restrict their efficiently utilize solar energy. Various efforts to enhance photocatalytic activity of $\mathrm{ZnO}$ NRs have been studied. It has been shown that the absorption of $\mathrm{ZnO}$ NRs can is extended to the visible region of the solar spectra by metal or non-metal ion doping (Ullah and Dutta, 2008), turning of defects in $\mathrm{ZnO}$ NRs (Akir et al., 2016; Baruah et al., 2009; Sarkar et al., 2012) or the growth rate of nanostructures (Sathe et al.,
2016). Among them an optimum defect by annealed in ambient is a most simple method. Defects in ZnO NRs include vacancies, interstitials or substitutions positions formation in the synthesis process. Those defects after optimum can create defect states between the valence band and the conduction band allows excitation of visible light to generate electron-hole pairs (Baruah et al., 2009; Kavitha et al., 2014).

In this study, we report the growth of $\mathrm{ZnO}$ Nanorod arrays ( $\mathrm{ZnO} \mathrm{NRs}$ ) on Aluminum-doped $\mathrm{ZnO}(\mathrm{AZO})$ thin film and their activity for the photodecomposition of Methylene Blue (MB) under UV and solar light irradiation. $\mathrm{We}$, also investigated the effect of annealed temperature on defects in $\mathrm{ZnO}$ NRs.

\section{MATERIALS AND METHODS}

Synthesis and Characterizations: ZnO NRs/AZO/TTO was synthesized by coupling an electrochemical deposition method and calcination method. Firstly, AZO thin film with $200 \mathrm{~nm}$ thickness and $65 \Omega^{2}$ was deposited on top ITO substrate by DC magnetron sputtering

Corresponding Author: Long Giang Bach, NTT Institute of High Technology, Nguyen Tat Thanh University, 298-300A Nguyen Tat Thanh, Ho Chi Minh City, Vietnam, blgiang@ntt.edu.vn 
system using $\mathrm{Al}_{2} \mathrm{O}_{3} 2$ wt.\%-doped $\mathrm{ZnO}$ target. The electrodeposition was carried out potentiostatically at an applied power of $56 \mathrm{~W}$ and Ar pressure of $3 \times 10^{-3} \mathrm{~T}$ orr, the fixed space between the target and substrate was $7 \mathrm{~cm}$. Then, the ZnO NRs prepared on AZO film through electrochemical deposition method (Voltage $2.4 \mathrm{~V}$ and current $1 \mathrm{~mA})$. Precursor solution containing $\mathrm{Zn}\left(\mathrm{NO}_{3}\right)_{2}$ $(5.0 \mathrm{mM})$ and $\mathrm{C}_{6} \mathrm{H}_{12} \mathrm{~N}_{4}(5.0 \mathrm{mM})$ was stirred at $85^{\circ} \mathrm{C}$ for $30 \mathrm{~min}$ before growing process. AZO thin film and a platinum wire served as the cathode and the anode, respectively. In addition, AZO thin film also set as seeding layers, so, ZnO NRs could grow up directly on it. Finally, the samples were rinsed with deionized water to remove precursor and annealed at several temperatures $100-500^{\circ} \mathrm{C}$ for $1 \mathrm{~h}$.

The morphology and size were observation by scanning electron microscopy (SEM, Hitachi S-4800). The $\mathrm{X}$-Ray Diffraction (XRD) patterns were performed using a Bruker D8 ADVANCE X-ray diffractometer. Photoluminescence (PL) spectra were collected on a Horiba iHR320 spectrometer using a xenon lamp as the excitation source at room temperature.

Photocatalytic test: The photocatalytic performances of $\mathrm{ZnO}$ NRs were studied by the photocatalytic degradation MB under visible light irradiation using a $300 \mathrm{~W}$ solar lamp Ultra Vitalux (Osram) and Ultraviolet light (UV) using an $8 \mathrm{~W}$ UV lamp. In the typical reaction, the sample was immersed in $10 \mathrm{~mL} \mathrm{MB}$ solution ( $5 \mathrm{ppm}$ ). Prior irradiation, the mixture was vigorously, stirred in the dark for $30 \mathrm{~min}$ to ensure adsorption-desorption equilibrium between the catalyst surface and $\mathrm{MB}$ molecules. About $3 \mathrm{~mL}$ of suspension was withdrawn at $15 \mathrm{~min}$ intervals for testing adsorption. The decrease in the $\mathrm{MB}$ concentration was measured on a UV-Vis spectrophotometer by recording the variations of the absorption band at $664 \mathrm{~nm}$.

The formation of hydroxyl radicals ( $\mathrm{OH})$ : The formation of hydroxyl radicals $\left({ }^{\circ} \mathrm{OH}\right)$ in the $\mathrm{ZnO} \mathrm{NRs} / \mathrm{AZO}$ system was detected by the fluorescence technique using Terephthalic Acid (TPA) as a probe molecule. When ${ }^{\circ} \mathrm{OH}$ radical generated from the visible light illuminated catalyst surfaces reacts with TPA, 2-Hydroxyterephthalic Acid (HTA) with a strong fluorescence characteristic at $425 \mathrm{~nm}$ peak was produced. The PL peak intensity of HTA is in proportion to the amount of $\mathrm{OH}$ radicals produced in water. The experiment processes were the same processes as the measurement of the photocatalytic test by replacing the aqueous solution of $\mathrm{MB}$ with the aqueous solution of TPA $(10 \mathrm{~mL}, \mathrm{TPA}=0.5 \mathrm{mM}$ and $\mathrm{NaOH}=2 \mathrm{mM}$ ). Fluorescence spectra were recorded on a Horiba iHR320 fluorescence spectrophotometer.

\section{RESULTS AND DISCUSSION}

Characterization and defects of ZnO NRs: The morphologies of $\mathrm{ZnO}$ NRs as grown were firstly studied by SEM technique as shown in Fig. 1a, b. From Fig. 1a, b, $\mathrm{ZnO}$ NRs possess morphology of hexagonal with an average diameter of 50-60 nm and the average length of 1.2-1.3 $\mu \mathrm{m}$; the crystals showed high-density uniform and the vertical orientation on top the substrate. The XRD pattern (Fig. 1c) confirmed that the ZnO NRs have the hexagonal wurtzite crystal structure. The strong shape peak at $2 \theta=34.5^{\circ}$ indicated the preferential orientation of the $\mathrm{ZnO}$ NRs along the (002) crystal plane. This suggests that ZnO NRs have a good crystal and c-direction.

The effects of annealing temperatures on surface defects in $\mathrm{ZnO}$ NRs were characterized by Photoluminescence (PL) (Fig. 1d). The luminescence of $\mathrm{ZnO}$ NRs includes two peaks. The UV peak at $380 \mathrm{~nm}$ corresponding to the violet emission, the main source of this emission is due to the band to band of $\mathrm{ZnO}$. However, $\mathrm{ZnO}$ band gap with $3.3 \mathrm{eV}$ is respected to $365 \mathrm{~nm}$ of violet emission. This position change can be explained due to the influence by $\mathrm{ZnO}$ excitation energy as large as $60 \mathrm{meV}$ and defect of Zinc interstitial $\left(Z_{\text {ni }}\right)$ energy level was found at $0.22 \mathrm{eV}$ under the conduction band (Alvi et al., 2011). Another peak broad at 500-700 nm was reported emission from the surface defects. The common defects in $\mathrm{ZnO}$ NRs structure consist of oxygen Vacancies $\left(V_{0}\right)$, zinc Vacancies $\left(V_{\mathrm{Zn}}\right)$, Oxygen interstitial $\left(\mathrm{O}_{\mathrm{i}}\right)$ and Zinc interstitial $\left(\mathrm{Z}_{\mathrm{ni}}\right)$. These peak bands are created by components of three shifts, recombination of hole and electron at oxygen Vacancies $\mathrm{V}_{\mathrm{O}++}$ at $585 \mathrm{~nm}$, recombination of holes and electron at $\mathrm{V}_{\mathrm{O}^{+}}$green emission at $530 \mathrm{~nm}$, chemical adsorption or desorption of oxygen, or $\mathrm{H}_{2} \mathrm{O}$ corresponding to orange-red shift $640-650 \mathrm{~nm}$ (Van Dijken et al., 2000; Hofmann et al., 2007; Tang et al., 2015) Fig. 1d indicated that when increasing the annealed temperature from $100-500^{\circ} \mathrm{C}$, the relative intensity of UV peak increased due to the completion of the $\mathrm{ZnO}$ NRs structure. In addition, we also observed that with a lower annealed temperature $\left(<300^{\circ} \mathrm{C}\right)$, the relative intensity of visible peak $(500-700 \mathrm{~nm})$ increased, leading to the formation of increase surface defects density. This source may contribute to geometrical characteristics of hexagonal wurtzite crystalline structure. 


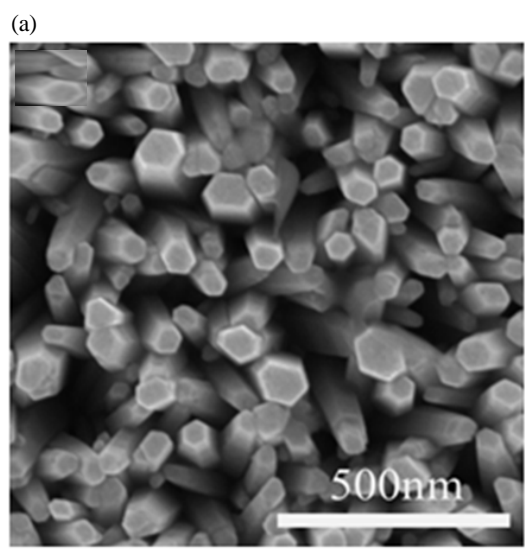

(b)
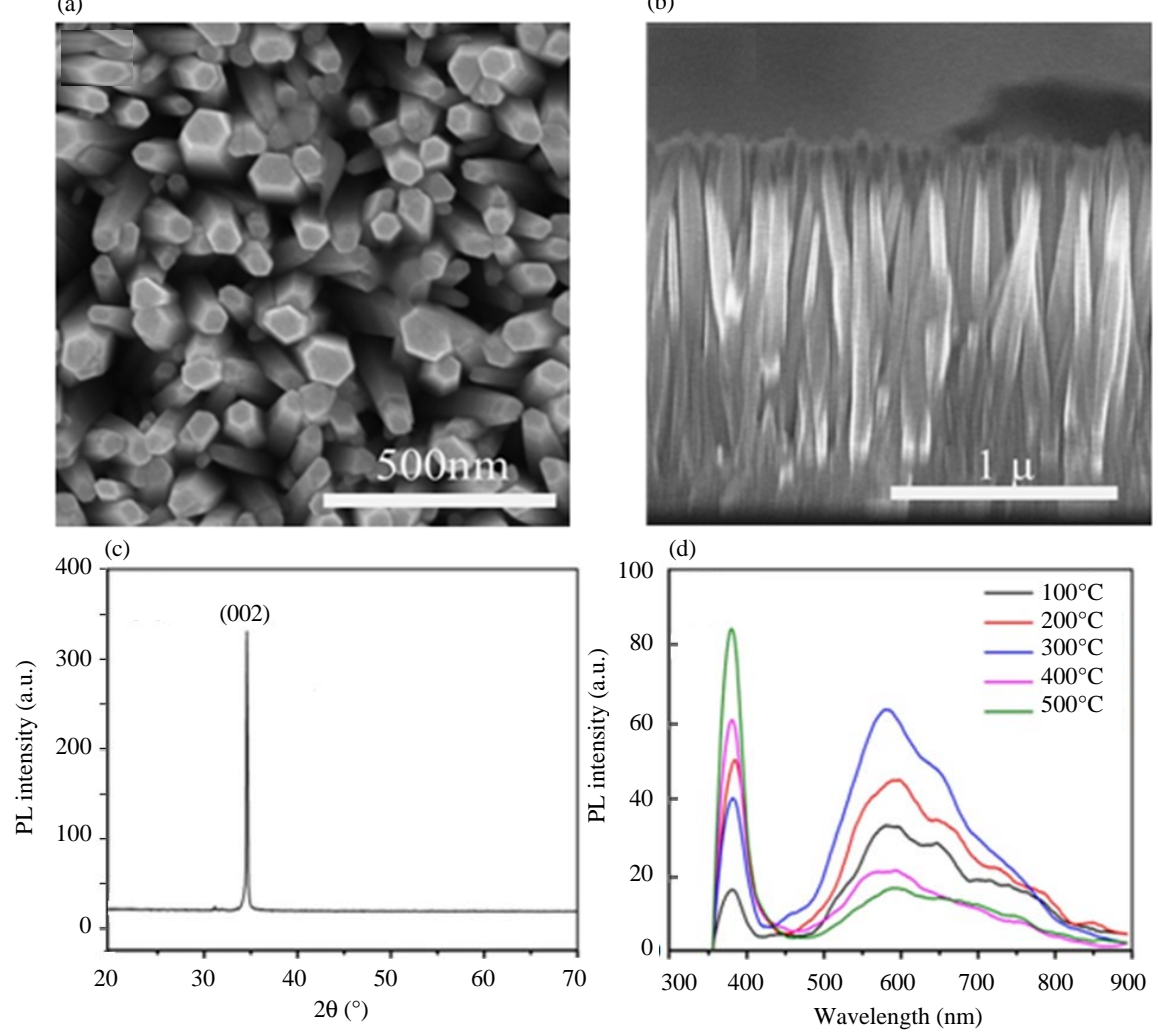

Fig. 1: a, b) SEM of ZnO NRs as grown on AZO electrodes using electrochemical deposition; c) XRD pattern of ZnO NRs as grown and d) Photoluminescence (PL) spectra of the $\mathrm{ZnO}$ NRs at several temperatures, $100-500^{\circ} \mathrm{C}$ obtained with excitation wavelength of $325 \mathrm{~nm}$

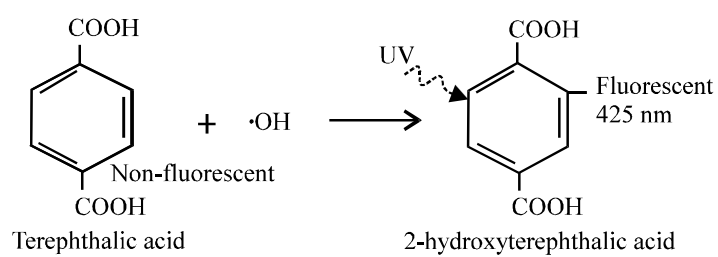

Fig. 2: Formation of 2-hydroxyterephthalic acid due to the reaction between terephthalic acid and hydroxyl radical of $\mathrm{ZnO} \mathrm{NRs}$ under visible light irradiation

The wurtzite hexagonal crystalline structure of $\mathrm{ZnO}$ NRs has the value for hexagonal cell $\mathrm{c} / \mathrm{a}=1.606$, the $\mathrm{c}$ axis being prioritized and the vertical (c-axis) energy required for crystal growth is small. So, diffusion of defects in structure will prioritize to this direction. When annealed temperature increases, $\mathrm{Zn}-\mathrm{O}$ bonding can be enhanced, so, the defects in structure, if $\mathrm{ZnO} N$ Rs will move to the surface. In this case, the increase of annealed temperatures from $100-300^{\circ} \mathrm{C}$ may conducive to the removal of oxygen vacancy defects to the surface, corresponding to the increase of intensity emission at $530-585 \mathrm{~nm}$. However, when the annealed temperature was increased to $400-500^{\circ} \mathrm{C}$, these defects at the surface were filled with oxygen in the air to complete the $\mathrm{ZnO}$ structure for that reason reduction emission intensity at this peak. The remarkably close correlation of annealed temperature on the surface defects in $\mathrm{ZnO}$ NRs which can be improved the visible light absorption.

The formation of hydroxyl radicals $(\mathrm{OH})$ and visible photocatalytic degradation of MB: Figure 3c shows the changes of PL spectra of TPA solution after $120 \mathrm{~min}$ exposed under visible light irradiation on $\mathrm{ZnO} \mathrm{NRs}$ samples. HTA with a strong fluorescence characteristic at $425 \mathrm{~nm}$ peak obtained by the reaction of TA with the - $\mathrm{OH}$ radical formed on the interface of the photocatalyst water during irradiation (Fig. 2).

As shown in Fig. 3c, a blue emission signal at approximately $425 \mathrm{~nm}$ was observed in the presence of a catalyst. $\mathrm{ZnO}$ NRs sample annealed at $300^{\circ} \mathrm{C}$ showed the highest intensity among all samples. As mention above, the PL peak intensity of HTA is in proportion to the formation rate of ${ }^{\circ} \mathrm{OH}$ radicals produced in water which shows a good correlation with the photocatalytic activity. 

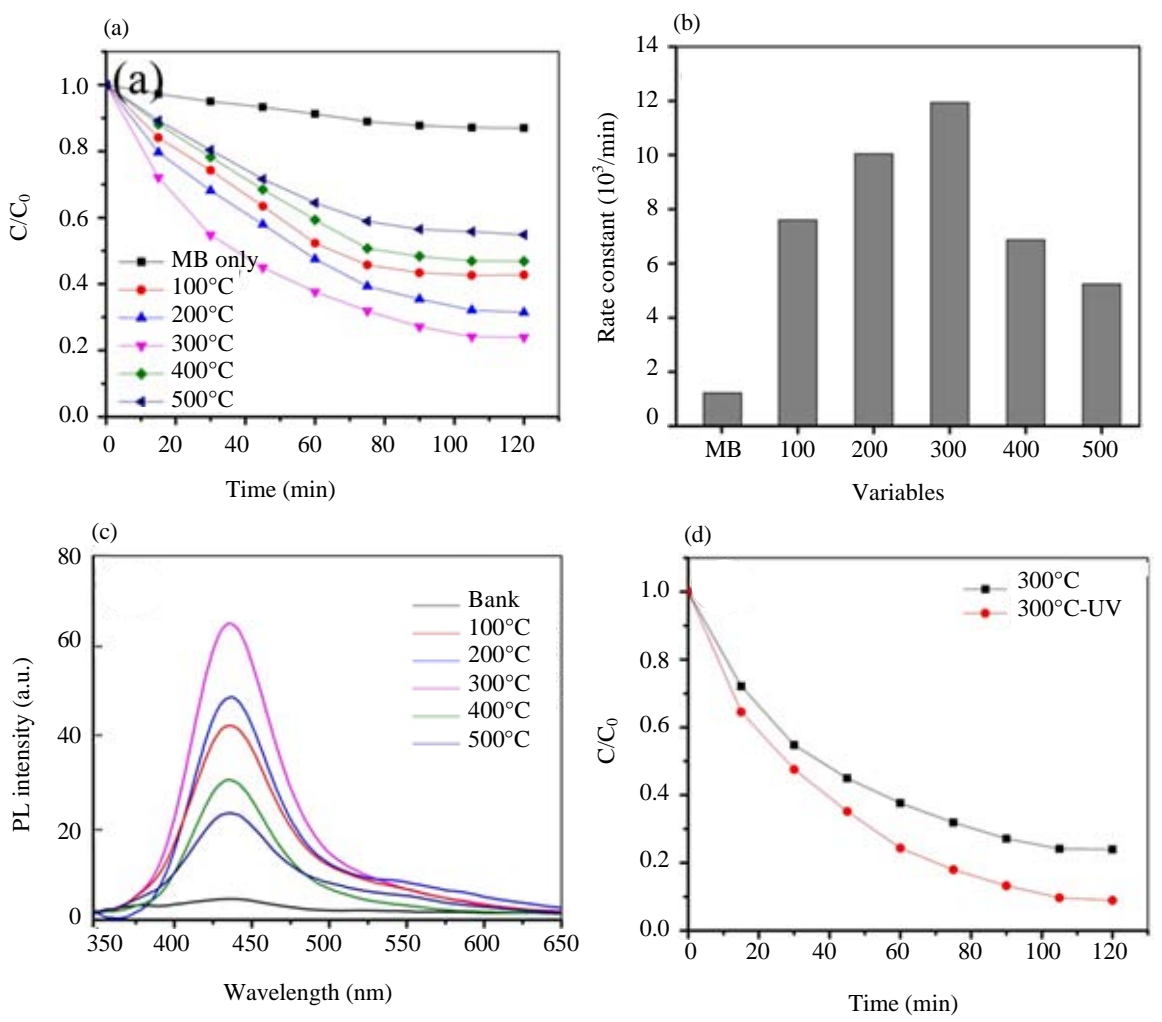

Fig. 3: a) Photocatalytic degradation chart of Methylene Blue (MB) solution under visible light irradiation with ZnO NRs photocatalysts annealed at different temperatures $\left(100-500^{\circ} \mathrm{C}\right.$ for $\left.120 \mathrm{~min}\right)$; b) Degradation kinetics of $\mathrm{MB}$; c) Photoluminescence (PL) spectra of terephthalic acid solution after 90 min exposed in visible light with ZnO NRs immersed and d) Photocatalytic degradation chart of Methylene Blue (MB) solution under UV and visible light irradiation with $\mathrm{ZnO} N R s$ photocatalysts annealed at $300^{\circ} \mathrm{C}$ for $120 \mathrm{~min}$

As shown in Fig 3a, ZnO NRs annealed at $300^{\circ} \mathrm{C}$ exhibited highest, about $76.05 \%$ of $\mathrm{MB}$ was decomposed after $120 \mathrm{~min}$ light on. The removal fraction of $\mathrm{MB}$ is about 68.58 and $57.27 \%$ for systems with the samples annealed at 200 and $100^{\circ} \mathrm{C}$, respectively. The samples annealed at temperature 400 and $500^{\circ} \mathrm{C}$ exhibited a decrease photocatalytic activities for $\mathrm{MB}$ degradation, accounting for 53.17 and $45.15 \%$, respectively. The rate constants $\mathrm{MB}$ photocatalytic degradation with differently annealed $\mathrm{ZnO} \mathrm{NRs}$ in Fig. 3b shows when increasing annealing temperatures up to $300^{\circ} \mathrm{C}$, the MB degradation rate constants was increased. While annealing temperatures higher than $300^{\circ} \mathrm{C}$, the degradation was reduced. This result correlated with visible light photocatalytic activity and surface defect states on ZnO NRs. Sub-bandgap formed from the surface that allows the transitions and generating active e-h pairs under visible light irradiation and thus, improve optical absorption (Al-Sabahi et al., 2016; Kavitha et al., 2014). However, when $\mathrm{ZnO}$ NRs were annealed at temperatures higher than $300^{\circ} \mathrm{C}$, the degradation rate constant was found increase. These results also support that can be optimum surface defects in $\mathrm{ZnO} \mathrm{NRs}$ to enhance efficiency photocatalytic in visible light.

$\mathrm{ZnO}$ NRs annealed at $300^{\circ} \mathrm{C}$ were exposed to visible light and UV light for comparison (Fig. 3d). Results after 120 min exposed degradation of $91.08 \% \mathrm{MB}$ under UV light and degradation $76.05 \%$ under visible light. This result shows the potential for photocatalytic application under the sunlight (including both UV and visible light) of this material after annealed with high efficiency.

\section{CONCLUSION}

We successfully, prepared $\mathrm{ZnO} \mathrm{NRs}$ by an electrochemical process using Al-doped $\mathrm{ZnO}$ film (AZO) as an electrode. As the results, the annealed temperature significant effects on the surface defects in ZnO NRs. $\mathrm{ZnONRs}$ sample annealed at $300^{\circ} \mathrm{C}$ exhibited the highest PL peak, having the highest formation rate of ${ }^{\circ} \mathrm{OH}$ radicals and showed excellent catalytic activity for the decomposition MB. 


\section{ACKNOWLEDGEMENT}

This research is funded by NTTU Foundation for Science and Technology Development under grant number 2017.01.15/HĐ-KHCN.

\section{REFERENCES}

Akir, S., A. Barras, Y. Coffinier, M. Bououdina and R. Boukherroub et al., 2016. Eco-friendly synthesis of $\mathrm{ZnO}$ nanoparticles with different morphologies and their visible light photocatalytic performance for the degradation of Rhodamine B. Ceram. Intl., 42: 10259-10265.

Al-Sabahi, J., T. Bora, M. Al-Abri and J. Dutta, 2016. Controlled defects of Zinc oxide nanorods for efficient visible light photocatalytic degradation of phenol. Mater., 9: 1-10.

Alinsafi, A., F. Evenou, E.M. Abdulkarim, M.N. Pons and O. Zahraa et al., 2007. Treatment of textile industry wastewater by supported photocatalysis. Dyes Pigm., 74: 439-445.

Alvi, N.H., K. U1 Hasan, O. Nur and M. Willander, 2011. The origin of the red emission in $\mathrm{n}-\mathrm{ZnO}$ nanotubes/p-GaN white light emitting diodes. Nanoscale Res. Lett., 6: 1-7.

Baruah, S., S.S. Sinha, B. Ghosh, S.K. Pal and A.K. Raychaudhuri et al., 2009. Photoreactivity of $\mathrm{ZnO}$ nanoparticles in visible light: Effect of surface states on electron transfer reaction. J. Appl. Phys., 105: 074308-074308.
Hofmann, D.M., D. Pfisterer, J. Sann, B.K. Meyer and R. Tena-Zaera et al., 2007. Properties of the oxygen vacancy in ZnO. Appl. Phys. A, 88: 147-151.

Kavitha, M.K., K.B. Jinesh, R. Philip, P. Gopinath and $\mathrm{H}$. John, 2014. Defect engineering in $\mathrm{ZnO}$ nanocones for visible photoconductivity and nonlinear absorption. Phys. Chem. Chem. Phys., 16: 25093-25100.

Look, D.C., 2001. Recent advances in $\mathrm{ZnO}$ materials and devices. Mater. Sci. Eng., B80: 383-387.

Sarkar, S., A. Makhal, T. Bora, K. Lakhsman and A. Singha et al., 2012. Hematoporphyrin-ZnO nanohybrids: Twin applications in efficient visible-light photocatalysis and dye-sensitized solar cells. ACS. Appl. Mater. Interf., 4: 7027-7035.

Sathe, P., M.T.Z. Myint, S. Dobretsov and J. Dutta, 2016. Removal and regrowth inhibition of microalgae using visible light photocatalysis with $\mathrm{ZnO}$ nanorods: A green technology. Sep. Purif. Technol., 162: $61-67$.

Tang, Y., H. Zhou, K. Zhang, J. Ding and T. Fan et al., 2015. Visible-light-active $\mathrm{ZnO}$ via. oxygen vacancy manipulation for efficient formaldehyde photodegradation. Chem. Eng. J., 262: 260-267.

Ullah, R. and J. Dutta, 2008. Photocatalytic degradation of organic dyes with manganese-doped ZnO nanoparticles. J. Hazard. Mater., 156: 194-200.

Van Dijken, A., E.A. Meulenkamp, D. Vanmaekelbergh and A. Meijerink, 2000. Identification of the transition responsible for the visible emission in $\mathrm{ZnO}$ using quantum size effects. J. Lumin., 90: 123-128. 